\title{
EM TEMPOS DE REDES E UBIQUIDADE: DESAFIOS PARA A EDUCAÇÃO'
}

\author{
Salete de Fátima Noro Cordeiro \\ Universidade Federal da Bahia (UFBA), Salvador, Bahia, Brasil \\ MARIA HelenA SILVEIRA BONILLA \\ Universidade Federal da Bahia (UFBA), Salvador, Bahia, Brasil
}

\begin{abstract}
Resumo: Abordamos a presença dos dispositivos digitais móveis no cotidiano escolar, tendo como problemática discutir perspectivas educativas baseadas na cultura digital e no protagonismo de seus praticantes. Objetivamos apontar elementos que colaborem para práticas educativas significativas à juventude e aos desafios contemporâneos. O estudo teve como base a pesquisa qualitativa, amparado na teoria dos cotidianos e cultura digital. Como resultados, temos: a falta de incentivo ao desenvolvimento da cultura digital nas escolas, que inibe a produção de conhecimentos, ao mesmo tempo que percebemos táticas de professores e alunos para utilizar os meios digitais. O potencial dessas tecnologias reside na criação de ambiências formativas pautadas por relações educativas mais horizontais e colaborativas.
\end{abstract}

Palavras-chave: Tecnologias Digitais. Mobilidade. Cotidianos Escolares.

\section{INTRODUÇÃO}

Há muito tempo as tecnologias digitais penetraram os cotidianos escolares e o fizeram de maneira tão avassaladora que não tivemos tempo de refletir sobre esse fenômeno, concomitantemente à sua chegada, nem sobre seus desdobramentos em termos de potencial educativo, ou sobre a maneira como iríamos passar a construir cultura, interagir com a ciência e rever as práticas que envolvem o aprender e o ensinar. Sabemos que a escola é uma instituição que muda muito lentamente ao longo da história, e o momento que estamos vivendo vem abalar tanto os modelos de currículos cristalizados quanto as relações verticalizadas e lineares dos processos de aprendizagem, que agora agonizam e suplicam por práticas que trabalhem em redes e de maneira colaborativa, sem perder de vista o sujeito e suas necessidades individuais.

O que tem chamado a atenção no cenário descrito acima é a presença intensa de dispositivos digitais móveis, que são aparelhos conectados, com crescente popularização, caracterizados pela portabilidade e convergência digital, o que possibilita ao interagente inúmeras opções de interatividade, entre elas navegar por sites e redes socais, baixar conteúdos, acessar apps, produzir imagens estáticas, vídeos ou áudios, editar e compartilhar. Isso significa que estamos diante de um momento potente em relação ao acesso, troca de informações e conhecimentos, onde o protagonismo não está voltado apenas para empresas de comunicação e jornalismo, mas para o cidadão comum, todo aquele que tem interesse por um fato ou uma temática. Outros aspectos 
importantes são a velocidade, o acesso e o compartilhamento de conteúdos, constituindo uma comunicação dinâmica e em rede.

Sabemos que muitas escolas, concomitantemente à chegada desses dispositivos, criaram normas internas para restringir sua utilização, ao mesmo tempo que muitos municípios e estados adotaram leis de proibição do uso desses aparelhos dentro das salas de aula. Podemos verificar essa tendência a partir dos casos de proibição oficial dos aparelhos celulares nas escolas: o primeiro estado a adotar as medidas legais foi São Paulo, através da Lei no 12.730, de 11 de outubro de 2007, que proibia qualquer aluno de utilizar os aparelhos durante o período de aula (SÃO PAULO, 2007), logo seguido por outros municípios no território nacional. No contexto atual, vivemos uma realidade completamente diferente daquela das proibições e cerceamentos. Diante da pandemia, que nos obrigou a permanecer em casa, enfrentamos a luta pela sobrevivência e pela garantia de educação a milhares de crianças e jovens, que nesse momento não podem frequentar a escola. Assim, as tecnologias, antes proibidas, estão sendo requeridas, incentivadas, valorizadas, como forma de manter a relação entre os alunos e as escolas e viabilizar a realização das atividades escolares.

O que percebemos nesse movimento são as grandes desigualdades de acesso às tecnologias, bem como de compreensão das suas potencialidades, ou seja, essas tecnologias e seus processos não deveriam ter sido excluídos do contexto escolar, mas fortalecidos, já que fazem parte da formação cidadã, para a vida e para o trabalho desses praticantes que vivenciam o cotidiano escolar. Apesar da revogação gradativa das leis proibitivas nos últimos anos, não houve tempo nem fortalecimento das políticas públicas que oportunizassem um forte movimento de incorporação das tecnologias nos processos pedagógicos. Em São Paulo, por exemplo, a lei que cerceava o acesso veio a ser revista em 2017, com a aprovação da Lei no 16.567, que revogou a lei anterior, por solicitação do secretário da Educação, José Renato Nalini, que em entrevista afirmou: "Se quisermos manter o aluno interessado em aprender, temos de usar a linguagem dele. A linguagem de seu tempo" (NALINI, 2017).

O argumento principal para tal decisão é a de que agora os aparelhos celulares poderão ser utilizados em sala de aula com finalidades pedagógicas e orientadas por educadores. Fica evidente nessa atitude o reconhecimento de que essa tecnologia é potente, faz parte da cultura e não pode ser refreada por decretos ou leis arbitrárias, mas o reconhecimento, apesar de importante, não é suficiente para mudanças nas práticas.

Os indicadores das pesquisas do Comitê Gestor da Internet no Brasil (2018a; 2018b), TIC Educação - 2018 e TIC Kids Online Brasil - 2018, mostram que 94\% de crianças e jovens de 9 a 17 anos utilizam, como principal fonte de acesso à internet, os aparelhos celulares. Em $91 \%$ dos casos o acesso é feito dentro da própria casa e apenas $33 \%$ realizado dentro das escolas. Os dados indicam que em $51 \%$ das escolas pesquisadas os alunos não têm acesso à senha do $\mathrm{Wi}-\mathrm{Fi}$, e apenas $16 \%$ delas disponibilizam esse sinal para toda a comunidade escolar. Mesmo que esses dados sejam totais e não mostrem especificidades regionais e por extratos sociais, o acesso restrito dentro dos ambientes educativos produz um impasse entre as vivências cotidianas dessas crianças e jovens, que configuram suas maneiras de aprender, 
relacionar, criar, compartilhar, pensar o mundo cada vez mais conectado e marcado pelas tecnologias digitais, e as oportunidades oferecidas pelas escolas voltadas à formação para o enfrentamento das problemáticas da vida e do mundo do trabalho.

Diante da totalidade de problemas apresentados, objetivamos, com este trabalho, trazer elementos para repensar as práticas conservadoras e engessadas, muitas vezes autoritárias, que estão em andamento nas escolas, a fim de que contemplem projetos de formação mais adequados a uma juventude conectada com o seu tempo.

Para discutir mais a fundo esse tema, vamos nos valer dos dados e reflexões construídos com base em uma pesquisa, em que acompanhamos os cotidianos de escolas públicas sendo alterados a partir da presença das tecnologias digitais móveis que chegavam, trazidas pela iniciativa governamental ou pelos próprios praticantes daqueles espaços. O objetivo foi compreender os saberes e processos construídos num cotidiano educativo no qual emergem, de diferentes maneiras, nem sempre sistematizadas e planejadas, as tecnologias digitais móveis. Neste trabalho focaremos, principalmente, em duas dessas escolas, onde presenciamos de forma intensa a participação dos dispositivos digitais móveis levados por alunos e professores, os quais, sem a mediação das instâncias governamentais, vão criando espaços/tempos instituintes de cultura digital.

As duas escolas em destaque, que fizeram parte da pesquisa, pertencem à rede municipal de educação, e tiveram o envolvimento de estudantes, corpo docente, coordenadores, diretores e funcionários. A escolha por alunos que estavam entre 0 quinto e nono ano do ensino fundamental, deu-se em função de que esse grupo era aquele que compreendia estudantes mais jovens, que portavam consigo o dispositivo móvel naquele momento. O envolvimento do pesquisador com todas as atividades promovidas pelas escolas foi fundamental para a construção de dados, incluindo reuniões gerais com pais e comunidade, reuniões de professores, festividades, intervalos, feiras de ciências e artísticas, implicação essa que possibilitou melhor compreensão daqueles contextos e uma aproximação mais intensa com os praticantes. Realizamos também conversas individuais e rodas de conversas com coletivos de alunos e professores, que foram gravadas em áudio e depois transcritas. As bases teóricometodológicas que deram sustentação ao trabalho estiveram embasadas em referenciais da pesquisa qualitativa, nas teorias dos cotidianos e nos estudos sobre cultura digital.

\section{TECNOLOGIAS DIGITAIS MÓVEIS NO COTIDIANO ESCOLAR}

Percebemos, durante nosso processo de investigação, relatos muito eloquentes, que manifestam essa entrada voraz das tecnologias digitais móveis na escola, como a de um funcionário da secretaria que observa o cotidiano sendo alterado de maneira repentina e profunda. Ele nos relata a chegada dos laptops como algo que tumultuou a escola, porque além do dispositivo que se apresentava como novidade tecnológica, havia a rede de internet, e por esse motivo os alunos queriam ficar para além de seu turno na escola ou voltarem a ela no fim de semana. Um dos diretores da escola enfaticamente menciona que, apesar de todas as dificuldades econômicas dos alunos e suas famílias, os celulares têm acompanhado esses estudantes há muito tempo, 
evidenciando que as tecnologias digitais móveis, levadas pelos alunos, já integram os viveres e fazeres dessa geração, sendo indissociáveis em suas vidas.

Os acontecimentos do cotidiano escolar não são mais os mesmos, pois tudo é alterado e ganha outros movimentos. A pura repetição, execução de normas e rotinas regulares é interrompida pelo fluxo da comunicação em rede, que não espera os ritmos dos espaços e tempos padronizados e hierárquicos. A intensidade com que as práticas comunicativas adentraram a escola criou desconforto, principalmente por parte dos adultos, professores e gestores, que não tiveram tempo de refletir sobre esse fenômeno, porque também estão imersos em diversas atividades que não são apenas as pedagógicas, como relata o diretor de uma das escolas: "Porque aqui a gente trabalha como delegado, assistente social a maior parte do tempo, a parte pedagógica nunca nem ouvi falar, sabe! [ironiza] E agora, a maior atividade atualmente, é administrar recursos." (Diretor B1). Não queremos culpabilizar os professores e a gestão da escola, mas chamar atenção para o fato de que sempre lhes foram atribuídas diferentes funções, entretanto sem as devidas condições necessárias. Sônia Penin (2011) fala-nos de vários tempos que se entrelaçam ao fazer educativo, entre eles o natural, cíclico, racional e linear, todos eles em uma trama que marca o trabalho administrativo e pedagógico, definindo seus ritmos e temporalidades.

Diante do contexto de cultura digital, onde estão presentes a internet, as redes e as relações aí construídas pelos sujeitos, distinguimos o surgimento de um outro tempo, o da ubiquidade, que vem fazer parte dessa trama de tempos, ritmos e movimentos que constituem o cotidiano escolar. Nesse tempo/espaço, que se torna mais flexível e programável, é possível reaprender a fazer uma educação que enalteça as diferenças, que valorize as possibilidades emergentes de interação entre os sujeitos, de relacionar, produzir e compartilhar conhecimentos. Sônia Penin (2011) fala da importância da aproximação dos tempos lineares aos naturais em contexto de aprendizagem. Para nós, o tempo da ubiquidade vem agregar-se a esses tempos, sem aniquilar nenhum deles, mas contribuindo com oportunidades mais diversificadas e ricas de pensar a educação e o cotidiano escolar.

Outra fala vem do diretor B2, que indica mais uma vez a intensidade com que as tecnologias móveis passam a fazer parte do cotidiano escolar. Mesmo com restrições de todos os tipos, os estudantes, e inclusive professores, fazem uso dos aparelhos a qualquer momento. “A gente não quer que o aluno atenda, mas o professor atende. Já conversamos com os professores a esse respeito. Mas observe, você está com o celular, você veio e tem alguém da sua família que ligou, você não vai atender?! "(Diretor B2). Na fala desse diretor, percebemos um ponto de vista que diverge muitas vezes do posicionamento dos gestores e professores. Aqui, a concepção de tecnologia digital móvel, de comunicação, já faz parte do cotidiano, de nossas vidas e não pode haver um momento offline, não há possibilidade de desligar o aparelho. Ele cita a família, a preocupação com filhos na escola, ou doença com familiares, uma emergência que venha a ocorrer, acontecimentos que não podem ser negligenciados. Portanto, o aparelho móvel deve permanecer ligado, pois ele estabelece uma ligação direta entre interlocutores. Na mesma fala é colocado em pauta o direito dos alunos usarem seus aparelhos, já que os professores estão utilizando, mesmo com orientação da escola para 
CORDEIRO, S. de F. N.; BONILLA, M. H. S.

que isso seja evitado. Para os alunos, já existe uma indissociabilidade entre suas vivências e a presença dos aparelhos móveis, que é marcada nas seguintes falas:

\begin{abstract}
Aluna B3: "Toda hora eu uso [...] Antes de vir pra cá, primeiro eu estava no Face, depois eu liguei [...] se eu ficar longe do celular eu morro. Eu gastei os bônus dela [do celular da colega] todinho. [Risos]." Aluna B4: "Foi. Fiquei numa raiva da peste."

Pesquisadora: "E você, pode deixar o celular em casa? Aluno C2: não. Pesquisadora: por quê? Aluno: não, porque senão eu morro. Eu não consigo viver sem meu celular não. Não tem como. Pesquisadora: por quê? Aluno: não sei. Não tem como. Só sei que não tem como. Pesquisadora: não tem como? Então você precisa muito dele. Que você faz durante a aula enquanto o professor está na sala? Aluno: largo ele. E quando o professor libera eu tô usando. Tô toda hora mexendo."
\end{abstract}

As vivências e relações estabelecidas com o digital por esses alunos indicam a necessidade de reflexão sobre um processo que não mostra nenhum indício de esgotamento, muito pelo contrário; se antes da pandemia, mesmo sofrendo vigilância e ameaças de punições, os alunos não relutavam em criar táticas de enfrentamento em ambientes de adversidade para viverem intensamente essa relação com o digital, no contexto atual, onde se incentiva a relação com os dispositivos para dar continuidade ao processo educativo, temos um contexto de fortalecimento de espaços mais flexíveis e conectados. Esse é o momento oportuno para pensar o potencial das tecnologias em rede na redefinição dos conceitos de educação, da estruturação dos currículos e rotinas escolares, pensando a dimensão comunicativa dos percursos formativos, de processos educacionais mais plurais, contextualizados e flexíveis.

\title{
DO ESPAÇO DISCIPLINADOR A OPORTUNIDADES DE LIBERDADE EDUCATIVA
}

Apesar de ser evidente que algo está acontecendo nesse cotidiano, e que não pode ser ignorado, durante a pesquisa observamos a postura reativa da escola, ao assumir-se proibitiva em relação à presença das tecnologias móveis e conectividade, sem sinalizar qualquer avanço em termos de discussão da segurança pessoal e de dados em rede, posturas éticas frente às dinâmicas que se estabelecem com o digital ou mesmo de formação de professores. Ao contrário, sua ação foi de negação e proibição de algo que não compreendia. Nas escolas investigadas, a orientação era de que o professor, ao ver seu aluno utilizando o aparelho em sala de aula, poderia pedir que a direção fizesse o recolhimento até que o pai, mãe ou responsável pelo estudante se apresentasse.

Um exemplo é o da escola $B$, onde o uso em sala de aula é proibido por orientação interna, e o procedimento fica claro na fala do diretor B1, que menciona a "apreensão" dos aparelhos: "Durante a aula, ao invés de ficar assistindo aula, estão ouvindo música ou jogando. Não é para isso que a gente está aqui. Então, pegou durante a aula usando o celular, o celular vai apreendido." (Diretor B1).

Dessa maneira, a escola, que deveria ser o espaço de problematização, de incentivo ao debate e construção de conhecimentos, assume discursos que envolvem as 
práticas penais, reforçando a função do espaço disciplinar. Foucault nos alerta que "O sistema escolar é também inteiramente baseado em uma espécie de poder judiciário. $\mathrm{A}$ todo momento se pune e se recompensa, se avalia, se classifica, se diz quem é o melhor, quem é o pior" (FOUCAULT, 2013, p. 118), tudo para controlar o comportamento dos praticantes, no intuito de manter e garantir a ordem e a disciplina. Ele ainda reforça essa ideia dizendo que:

\begin{abstract}
As pessoas que dirigem essas instituições se delegam o direito de dar ordens, de estabelecer regulamentos, de tomar medidas, de expulsar indivíduos, aceitar outros [...] nessas instituições não apenas se dão ordens, se tomam decisões, não somente se garantem funções como a produção, a aprendizagem, etc., mas também se tem o direito de punir e recompensar, se tem o poder de fazer comparecer diante de instâncias de julgamento (FOUCAULT, 2013, p. 118).
\end{abstract}

Se, por um lado, a escola é tomada de surpresa e assume certo embaraço diante da situação, que é resolvida com medidas atenuantes, por outro lado as instâncias legais reforçam a criminalização. Aqui percebemos um dispositivo do Estado que atua como um instrumento disciplinador e de maneira hierárquica, parecendo não refletir sobre o objeto e as causas do conflito instalado. Ele penetra nas temáticas e problemáticas que envolvem o campo educativo institucionalizado para tentar resolver, de maneira pragmática, as consequências de um processo que pouco ou nada se compreende. E foi nesse contexto de conflitos escolares entre professores, alunos e uso de tecnologias que acabaram se proliferando pelo país leis que institucionalizaram a proibição dos aparelhos celulares e congêneres dentro dos espaços formais educativos, a menos que fossem utilizados específica e restritamente para "fins educativos".

A prática proibitiva de São Paulo foi seguida por outros municípios e estados, em todo o território nacional, onde os legisladores não possuem a prática de discutir a fundo sobre os problemas que envolvem a educação pública e parecem encontrar, no uso das tecnologias móveis dentro da escola, a justificativa para os problemas educacionais. Muitos desses mesmos estados que proibiram o uso do celular estão agora abrindo suas portas de maneira indiscriminada para as plataformas educacionais, que oferecem serviços "gratuitos", e, com o cadastro de alunos da educação básica e do ensino superior, fazem um absurdo processo de coleta de dados, o que provoca um outro debate sobre vigilância, a algorítmica, mas esse tema trataremos em outro artigo. O que foi negado e até proibido, sem discussão e debates sociais sérios, agora reverbera em um sistema educacional despreparado para enfrentar o desafio de continuidade e de fortalecimento da educação, mesmo em situação de isolamento físico.

Entre as argumentações que sustentaram as leis proibitivas e perfilaram em artigos e debates em torno do tema, estava a de que a presença dos dispositivos móveis dentro da sala de aula configurava-se em um dos principais problemas enfrentados pelos professores no Brasil, pois estaria tirando a atenção dos alunos, focada nos conteúdos transmitidos pelos professores e no desenvolvimento de tarefas, para ouvirem música, entrar em redes sociais, jogar e interagir com os colegas através de 
aplicativos, dentre outros. No entanto, discordamos dessa argumentação, pois atribuir aos dispositivos móveis as mazelas educacionais não parece admissível, nem ao menos coerente.

Os problemas que afetam a educação vão bem além do movimento causado pela presença dos dispositivos de informação e comunicação portáteis, e, portanto, não podemos considerá-los admissíveis como argumento. Eles estão também na esfera macro da sociedade, que envolvem políticas públicas de expansão da oferta sem a devida melhoria da qualidade do que é oferecido. Isso significa maiores investimentos em infraestrutura, formação e valorização de professores e fomento em outras áreas como cultura, tecnologias e melhoria de qualidade de vida da população em geral. Não nos parece coerente, pois, ao mesmo tempo em que essas leis foram sendo aprovadas em cada estado, o Governo Federal vinha incentivando, através de projetos e programas, a disseminação desse mesmo modelo de tecnologia digital móvel, através dos laptops e tablets nas escolas públicas. Incoerência e falta de articulação evidentes entre políticas públicas que envolvem um projeto de educação, que não pode ser concebido por apenas um ministério ou um ente federado, mas deve fazer parte de um projeto de nação.

A adoção de leis que proibiram o uso de tecnologia dentro dos espaços educativos impediu que essas escolas desenvolvessem sua experiência na cultura digital. A ausência de redes de banda larga e formação de professores nesse campo retraiu a criação de propostas pedagógicas e didáticas que partissem dos cotidianos escolares, ou seja, matou no nascedouro a dimensão social e cultural do uso dessas tecnologias, as quais, uma vez inseridas nas escolas, deveriam fazer parte da própria reflexão e construção de outros saberes, de outras experiências e práticas educativas, para além da rigidez do currículo que se impõe a cada dia, em cada cotidiano.

As escolas precisam estar conectadas com o mundo, não podem viver um apagão em termos de acesso e conectividade, ter conectividade precária ou nenhuma conectividade, ou mesmo, ter sites e redes bloqueados ou proibidos. Segundo Pretto (2018, p. 03), "vivemos um momento de intensa luta política, onde a internet está desempenhando um papel central, estando ela própria no foco dos debates contemporâneos. Conectar a escola à internet e usá-la plenamente é parte imprescindível da formação das juventudes". A manifestação do autor está relacionada à ação da Secretaria Municipal de Educação de Salvador (SMED) em proibir mais de 30 sites e redes sociais dentro das escolas e de seu próprio órgão central. Mais interessante é que essa decisão foi tomada há menos de dois meses da instituição do Programa de Inovação Educação Conectada pelo Ministério da Educação, que tem por objetivo fomentar o uso pedagógico de tecnologias digitais na Educação Básica, formação de professores e conectar com internet de alta velocidade as escolas do meio urbano e rural em todo o país até 2024.

Importante lembrar que mesmo a escola não dispondo ou disponibilizando de forma precária essas tecnologias, elas têm chegado através dos aparelhos móveis, que entram de maneira avassaladora dentro do espaço educativo e são utilizados de maneira completamente incontrolável, tanto para ouvir música e para comunicação nas redes sociais quanto para games, etc. Isso causa um movimento incontrolável não só dos corpos sentados que estão em outro movimento o tempo todo (dedos nervosos no 
teclado, olhos nas telinhas, sentidos em alerta), mas também do pensamento dos alunos que pode estar em qualquer espaço ou tempo, além da sala de aula.

Percebemos que muitos professores, e a escola de maneira geral, sentem-se reféns, não se sentem seguros, nem preparados para abraçar essa realidade de maneira vigorosa, com propostas de trabalho, fundamentação teórica e argumentação para o próprio convencimento da comunidade escolar. A opção das escolas e do poder público foi então de, sem compreender esse contexto, negar e proibir o uso dos dispositivos. Segundo Foucault, uma das funções das instituições, como a escola, não é apenas controlar o tempo e os corpos dos praticantes, o corpo "deve ser formado, reformado, corrigido, [...] deve adquirir aptidões, receber um certo número de qualidades, qualificarse como corpo capaz de trabalhar" (FOUCAULT 2013, p. 117). A presença dos dispositivos, nesse contexto, é a prova da "contravenção" ou "infração", ou seja, são eles os elementos que conduzem à indisciplina, à falta de interesse nas aulas e aos baixos rendimentos nos testes internos e externos. A lei, formalmente estabelecida, construída através de um discurso que pretende garantir a melhoria da qualidade da educação, através da atenção e concentração dos alunos nos conteúdos e nos professores, reforça a manutenção dos processos de reprodução social. Segundo Foucault (2013), as instituições têm por finalidade "fixar os indivíduos", assim:

[...] a escola não exclui os indivíduos; mesmo fechando-os; ela os fixa em um aparelho de transmissão do saber... em um aparelho de normalização dos homens. A fábrica, a escola, a prisão ou os hospitais têm por objetivo ligar o indivíduo a um processo de produção, de formação ou de correção de produtores. (FOUCAULT, 2013, p. 113).

Fixar os praticantes a um único modelo de educação, no momento em que vivemos a intensificação da cultura digital e que esses dispositivos que cabem na palma da mão, trazidos pelos praticantes, podem acessar museus, bibliotecas, portais de periódicos de referência nacional e internacional, estabelecer diálogo e criação com vários grupos e outros praticantes ao redor do mundo, não parece honesto/justo, é segregador e excludente. A convergência desses dispositivos possibilita não apenas o acesso, mas a captura e produção de conteúdos que, depois de editados, ou não, podem ser compartilhados. Com o digital, os momentos de escassez de conteúdos são dirimidos e as possibilidades de mais pessoas terem acesso aos mesmos e a usufruírem da cultura produzida pela humanidade tornam-se uma realidade.

Diante do que estamos vivenciando, das possibilidades de inserção desses praticantes na cultura digital, que pode acontecer a partir de seus próprios aparelhos ou dos dispositivos presentes nas escolas, sendo utilizados como estruturantes dos processos educativos, precisamos dialogar com as escolas, com seus praticantes, verificar em seus cotidianos quais são suas demandas e junto com elas criar enfrentamentos para a construção de alternativas que envolvam a perspectiva cultural, comunicativa, colaborativa e que tenham no horizonte a construção de seres fortalecidos do ponto de vista democrático e cidadão. 
CORDEIRO, S. de F. N.; BONILLA, M. H. S.

VALORIZANDO EXPERIÊNCIAS E PRODUZINDO SABERES: PRECISAMOS ESTAR CADA VEZ MAIS EM REDE

Os processos educativos passam a operar no que chamamos de espaços e tempos ubíquos, que funcionam como linhas de fuga, em que os praticantes exercem suas táticas e podem cocriar imprimindo dinâmicas e ritmos próprios ao construir conhecimentos, saberes e cultura. Entram em jogo outros sentidos, estéticas e linguagens, favorecendo as trocas, sejam elas simbólicas ou de conteúdos. Temos presentes territorialidades produzidas em espaços e tempos de interação, desenvolvidos sob a metáfora da rede.

Para Alves (2008), a rede, na contemporaneidade, vem problematizar e provocar, de maneira enfática, as formas de produzir conhecimento. Para a autora, a rede substitui a ideia da construção de um conhecimento que necessita seguir etapas ordenadas e sequenciais, de via única que segue um modelo obrigatório baseado ainda na hierarquia e linearidade (ALVES, 2008).

Para Ferraço (2008), as redes são constituídas de significados, nos quais os diversos contextos criam a trama intercultural, rica de saberes e vivências que habitam o cotidiano da escola. $\mathrm{O}$ autor enfatiza que todo conhecimento que se queira compreender ou construir dentro da escola deve partir da ideia de valorizar a cultura do outro, seus saberes, suas vivências, seus modos de fazer e ser. Assim, ao adentrar o cotidiano escolar e pensar em atividades de interação ou intervenção, devemos ter em consideração o que ali já acontece, o que foi construído, seus processos e práticas: "as redes só existem enquanto são tecidas. Não são resultados, não são produtos, não existem enquanto elementos particulares, quantificáveis. Elas se esgotam, se desfazem, durante o próprio processo de produção" (FERRAÇO, 2008, p. 119). A construção das práticas pedagógicas e dos currículos se constroem nesse devir, onde nada é sólido para sempre, mas está aberto ao enfrentamento e à construção de novos sentidos, saberes, percepções e conhecimentos. A disposição dos professores e das escolas pesquisadas em estarem com todos os seus sentidos atentos e abertos a ressignificações possibilitou a observação de um cotidiano em movimento, e consequentemente aberto a mudanças em suas práticas diante da presença das tecnologias digitais móveis e dos dispositivos trazidos pelos alunos. Vamos acompanhar o relato dos professores de duas escolas:

[...] foi um projeto sobre o nosso bairro, [...] e alguns deles [estudantes] fizeram vídeo. [...] eles apresentaram o vídeo, teve algumas turmas também que apresentaram um $C D$, então, eles que fizeram. [...] Estamos marcando uma série de excursões para museus [...] Nós vamos começar pelo Palácio do Museu, vamos colocar pra eles produzirem produtos de comunicação sobre o Museu e sobre o que eles viram lá, e eles vão levar as maquininhas [smartphone] pra filmar, fotografar [...] (Professor C3).

$O$ que a gente precisa é aproveitar, porque onde que a gente aprende mais? É pesquisando. Eu digo, gente! Gente! Usem a internet para a pesquisa. Eu como professora eu pesquiso. Em sala de aula, teve essa experiência da pesquisa de autoestima e teve outra, de adjetivo, que a gente estava falando sobre adjetivo e tinha um menino fazendo aniversário, e era do signo de Touro. E aí, outro me mostrou um site dos signos, MA-RA-VI-LHO-SO! Que eu fiquei 


\begin{abstract}
assim encantada. "Gente, olha aqui!" Aí comecei as características do signo de Peixes, [...]. Comecei muito empolgada, e eles adoraram [...] Então eu penso que a tecnologia, ela tem que estar próxima, e nós como professores, devemos ter aquele joguinho de cintura para não perder essas oportunidades. (Professora B2).
\end{abstract}

Percebemos a sensibilidade desses professores que começam a repensar suas práticas e seu planejamento a partir do que percebem das vivências cotidianas de seus alunos com essas tecnologias. Esses professores não passaram por nenhuma formação específica para a incorporação das tecnologias móveis em suas rotinas didáticas, nem ao menos tiveram a chance de discutir com seus colegas de trabalho as possibilidades ou não de uso, uma vez que esse não era um tema considerado prioridade nas reuniões pedagógicas, e, inclusive, em uma das escolas o uso de dispositivos móveis pessoais era proibido, por norma interna. Apesar das circunstâncias desfavoráveis, estão surgindo outros olhares e ações nas práticas pedagógicas dessas escolas.

A vivência do professor C3, por exemplo, mostra que os alunos, ao irem a campo realizar a tarefa de pesquisa determinada em classe, extrapolam o roteiro de trabalho, que era inicialmente de produzir relatórios escritos. Os suportes digitais de que dispõem possibilitam que os alunos tomem a iniciativa e produzam vídeos com uma narrativa que faz a denúncia sobre a situação de abandono e descuido do local onde vivem. Com a linguagem das fotografias, também feitas com seus aparelhos celulares e smartphones, produzem uma maquete e contam a história do seu bairro através do olhar curioso e de achados inusitados captados pelas pequenas lentes. Quando os alunos apresentam aos seus professores esses conteúdos, que chegam com um outro processo de produção e em outros formatos, misturado com autonomia e criatividade, retiram os seus professores de uma área de conforto, uma vez que não há mais como voltar atrás. O professor mesmo diz que, no próximo evento, já vai incorporar o digital aos processos. Uma vez incorporado, outras demandas vão surgindo, pois o digital vai exigir não apenas a captura de dados e informações, mas o tratamento e edição dos mesmos, como na criação de vídeos, imagens ou podcasts.

As falas só vêm reforçar como tem acontecido a formação dos professores e como renovam sua prática através de processos reflexivos dados no cotidiano. Esse processo rico, invisibilizado muitas vezes, acontece quase que de maneira solitária, se não fosse a vivência partilhada com seus alunos e alunas. Percebemos que a postura é de abertura, de curiosidade, eles vão experimentando, tateando, não possuem um conhecimento teórico que os embasem, mas estão apostando na experiência que emerge desse cotidiano caótico. Por isso não podem estar sozinhos nessa caminhada, uma vez que as práticas que envolvem a cultura digital lançam desafios cada vez mais instigantes para a educação, professores e escolas públicas.

As experiências que trazemos a partir da pesquisa, são apenas indícios de muitas outras que estão sendo criadas e vivenciadas dentro das escolas. São experiências forjadas a partir do cotidiano turbulento que enfrentam professores e as próprias escolas públicas, que apesar disso fazem muito, mas ainda não têm oportunidades de visibilidade de seu trabalho. Lembramos das palavras de Pretto (2013), quando menciona que não apenas a internet deve estar na escola, mas a escola deve 
estar na internet. Isso significa que toda a cultura produzida dentro da escola, ou produzida por ela fora de seus muros, incluindo suas comemorações, as ações, os projetos, as propostas, deve ter a possibilidade de ser divulgada e compartilhada. Para isso, sugerimos utilizar todos os meios disponíveis que possam valorizar e dar visibilidade ao que acontece e é produzido por professores, alunos e comunidade envolvida. Santos (2007) fala-nos da importância de valorizar essa experiência, que muitas vezes fica invisível: "Experiências muito locais, não muito conhecidas, nem legitimadas pelas ciências sociais hegemônicas, são hostilizadas pelos meios de comunicação social, e por isso têm permanecido invisíveis, 'desacreditadas'"' (SANTOS, 2007 , p. 24) e, hoje, para ter essa valorização da experiência é preciso de visibilidade, precisamos ir além dos materiais analógicos produzidos pelas escolas, precisamos colocá-los no formato digital e em rede. O poder que os sujeitos têm de serem produtores de conteúdos é muito forte, pois ninguém mais que os próprios praticantes ou coletivos para falar por eles mesmos, criar suas narrativas, defender suas ideias, construir resistências outras, através de um protagonismo em rede.

A presença das tecnologias digitais móveis traz um alargamento para as práticas e experiências de um cotidiano escolar que não acontece mais somente dentro da escola, mas também no seu espaço físico externo, virtual e em redes. Os dispositivos, conectados ininterruptamente, possibilitam aos estudantes atividades simultâneas que envolvem estar nas suas redes sociais, e ao mesmo tempo registrando por áudio ou imagem a aula do professor, pesquisando um conteúdo ou verbete, fazendo resumos e compartilhando entre si. Assim, o tempo/espaço de aprender é ampliado para outros territórios, onde possam estar com seus fones, ouvindo músicas, jogando, assistindo a vídeos, trocando ideias ou informações, e, para além disso, compreendendo a lógica desses processos e linguagens. Provém desse movimento a necessidade da escola assumir-se enquanto espaço formativo, promovendo a discussão constante, tanto oportunizando a problematização crítica das mazelas que a acompanham, tais como a invasão de privacidade e uso de dados, as Fake News, o Ciberbullying, ou qualquer outro tipo de violência em rede quanto buscando a compreensão do potencial de inovação e aprendizagem trazido por essas tecnologias, como os trabalhos colaborativos, o remix, a produção e o compartilhamento de conteúdos.

Agora, com a pandemia, é requerido que a escola assuma esse protagonismo, que se aproprie das tecnologias para repensar suas práticas, para oportunizar formações mais consistentes, tanto para os professores como para os alunos. Não basta migrar as mesmas atividades que eram desenvolvidas presencialmente para os ambientes digitais, exigindo que os alunos permaneçam horas, agora em casa, realizando-as, sob a supervisão de algum familiar. Temos a oportunidade de, inspirados nos movimentos dos alunos, nas escolas, quando lá estavam presentes, construir outros sentidos para essas tecnologias e para a educação, uma educação que não se paute apenas no uso das tecnologias para a transmissão de conhecimentos, mas que se centre na formação do cidadão que está enfrentando uma série de tensões no contexto atual, sejam elas de ordem social, econômica, de saúde, e que precisa de suporte para enfrentar os desafios que tem pela frente.

Para Certeau (2008), a produção das maneiras de viver é construída no cotidiano, através do embate entre praticantes que jogam através de táticas e estratégias, que lutam pela defesa de seus interesses e sobrevivências do dia a dia. É a 
partir do tensionamento dos cotidianos, das práticas diárias que uma poiética é criada e com ela outros modos de fazer, de ser, representar e estar no mundo.

Os cotidianos escolares que estudamos estão impregnados por práticas que envolvem as tecnologias digitais móveis, algumas mais sistematizadas, outras menos, mesmo assim, são espaços ricos em termos de produção de saberes, de maneiras de fazer que merecem atenção. Marcados por embates e pelo jogo de forças travado, constituem-se como espaços/tempos de transformações, rupturas, descontinuidade, invenção e resistência. É o que mais necessitamos agora!

\section{CONSIDERAÇÕES FINAIS}

Como a chegada das tecnologias digitais móveis não é acompanhada de uma problematização sobre seus limites e possibilidades, são criadas polaridades entre o uso e não uso, o pode e não pode, o permitido e não permitido. Os temas inerentes a elas, tais como os usos pelos alunos, as redes sociais, Ciberbullyng, segurança na rede, entre tantos outros, deveriam fazer parte da preocupação da escola como um todo, e assim ocupar o currículo escolar. Por outro lado, deveríamos refletir sobre o que essas tecnologias representam do ponto de vista da própria construção do conhecimento, tanto no que se refere ao acesso a conteúdos e conhecimentos já produzidos quanto ao espaço de reconstrução ou produção dos mesmos, bem como de seu compartilhamento.

Entendemos, portanto, que aquilo que parece atrapalhar os processos educativos, a atenção e concentração, também é fonte de construção de saberes, de acesso a uma diversidade de linguagens e informações. Tendo como ponto de partida um aparelho digital móvel podemos acessar repositórios, enciclopédias digitais, obras artísticas, artigos, vídeos, animações, mapas, além de também podermos produzir nossos próprios conteúdos. Isso tudo porque estamos falando de dispositivos que têm como característica a hibridação. Não são apenas canais de informação e comunicação. São pequenas ilhas de edição e compartilhamento, o que para nós é o mais interessante, pois coloca a possibilidade de protagonismo e autoria em um patamar nunca antes possível.

À medida que acompanhamos sistematicamente esse cotidiano intenso, vivo, prenhe de múltiplas experiências e de vivências, podemos perceber quanta vida pulsante há nessa escola, um espaço que se torna vigoroso de reelaboração própria e singular. Por esse e tantos outros motivos, a escola não pode ser desmerecida, tomada como um espaço neutro, caracterizado pela mera repetição e reprodução. Percebemos que existem processos reflexivos pujantes, nos quais professores e alunos não podem ser ignorados, tendo em vista a riqueza de experiências provenientes desse cotidiano de dificuldades, embates e enfrentamentos. Portanto, necessitamos ouvir as comunidades escolares e discutir com elas, saber suas demandas, construir pautas conjuntamente e criar o enfrentamento necessário às questões educativas, culturais e formativas.

A escola precisa ser compreendida e assumir-se como espaço formativo por excelência, onde participam e trocam saberes professores, alunos, comunidade e academia. Nesse sentido, o potencial das tecnologias digitais em rede colabora para 
CORDEIRO, S. de F. N.; BONILLA, M. H. S.

repensar os conceitos de educação, reelaboração dos currículos e dos percursos formativos.

A partir do nosso estudo, pudemos perceber uma dinâmica potente que envolve as experiências do cotidiano e as diversas formas de saberes, que uma vez estando em relação, formam redes de informação e conhecimento, tornando o espaço educativo da escola numa tessitura complexa e interconectada com o que acontece tanto no seu interior como para além de seus muros. Isso nos leva a pensar os processos que envolvem o ato educativo, a partir das significâncias, dos atos, das pautas, dos desejos de cada comunidade escolar na sua relação com o mundo, o que decorre da proposição de uma postura de abertura com o diferente e de enfrentamento dialógico como as pautas que vêm de fora, mas que ressoam no cotidiano escolar de maneira peculiar, nos modos de interagir, produzir conhecimento e sentidos, compreender e reelaborar a vida a partir da cultura digital.

Artigo recebido em: 03/08/2020

Aprovado para publicação em: 09/10/2020

\section{IN TIMES OF NETWORKS AND UBIQUITY: CHALLENGES FOR EDUCATION}

ABSTRACT: This is a clipping of a doctoral thesis, updated in the light of the pandemic context. It addresses the presence of broadband and mobile devices in school life. The objective was to understand the knowledge constructed in the educational routine of public schools with the presence of mobile digital technologies. This study was based on qualitative research, supported by the theory of everyday life and digital culture. As a result, we have: the growing restriction of technologies through prohibitive actions; and tactics of teachers and students to use them. The potential of these technologies lies in the creation of more horizontal educational relationships and the construction of content, knowledge and knowledge.

KEYWORDS: Digital Technologies. Mobility. School Routine.

\section{EN TIEMPOS DE REDES Y UBIQUIDAD: DESAFÍOS PARA LA EDUCACIÓN}

RESUMEN: Este es un recorte de una tesis doctoral, actualizada a la luz del contexto pandémico. Aborda la presencia de banda ancha y dispositivos móviles en la vida escolar. El objetivo era comprender los saberes construidos en el cotidiano educativo de las escuelas públicas con la presencia de tecnologías digitales móviles. El estudio se basó en la investigación cualitativa, respaldada por la teoría de los cotidianos y la cultura digital. Como resultado, tenemos la creciente restricción de las tecnologías a través de acciones prohibitivas y el desarrollo de tácticas, por parte de maestros y estudiantes, para usarlas. El potencial de estas tecnologías radica en la creación de relaciones educativas más horizontales y en la construcción de contenidos, conocimientos y saberes. 
PALABRAS CLAVE: Tecnologías Digitales. Movilidad. Cotidianos Escolares.

\section{REFERÊNCIAS}

ALVES, N. Tecer conhecimento em rede. In: ALVES, N.; GARCIA, R. L. (org.). O sentido da escola. $5^{\text {a }}$ ed. Petrópolis: DP et Alii, 2008. p.91-99.

ALVES, N. et al. Criar currículo no cotidiano. 3ª ed. São Paulo: Cortez, 2011.

COMITÊ GESTOR DA INTERNET NO BRASIL. TIC Educação - 2018: Indicadores. 2018a. Disponível em: http://cetic.br/pesquisa/educacao/indicadores. Acesso em: 18 abr. 2020.

COMITÊ GESTOR DA INTERNET NO BRASIL. TIC Kids Online Brasil - 2018: Indicadores. 2018b. Disponível em: http://cetic.br/pesquisa/kids-online/indicadores. Acesso em: 18 abr. 2020.

CERTEAU, M. de. A invenção do cotidiano: 1.artes do fazer. Traduzido por Ephraim F. Alvez. 15a ed. Petrópolis: Vozes, 2008.

FERRAÇO, C. E. Currículos e conhecimentos em redes: a artes de dizer e escrever sobre a arte de fazer. In: ALVES, N.; GARCIA, R. L. (Org.). O sentido da escola. $5^{\text {a }}$ ed. Petrópolis: DP et Alii, 2008. p. 101-124.

FOUCAULT, M. A verdade e as formas jurídicas. Tradução: Eduardo Jardim e Roberto Machado. Rio de janeiro: Nau, 2013.

LEFEBVRE, H. A vida cotidiana no mundo moderno. Tradução: Alcides João Barros. São Paulo: Ática, 1991.

NALINI, José Renato. Alckmin libera celular em escolas estaduais para fins pedagógicos [07/11/2017]. Gazeta Online. Disponível em: https://www.gazetaonline.com.br/noticias/brasil/2017/11/alckmin-libera-celular-emescolas-estaduais-para-fins-pedagogicos-1014106470.html. Acesso em: 18 maio de 2020.

OLIVEIRA, I. B.; SAGARBI, P. Estudos do cotidiano e educação. Belo Horizonte: Autêntica, 2008.

PENIN, S. Cotidiano e escola: a obra em construção. 2a ed. São Paulo: Cortez, 2011.

PRETTO, N. D. L. Internet proibida na Educação em Salvador, Jornal $\boldsymbol{A}$ Tarde, Salvador, 13 jan. 2018, p. 03. 
CORDEIRO, S. de F. N.; BONILLA, M. H. S.

PRETTO, N. D. L. Uma escola sem/com futuro: educação multimídia. EDUFBA: Salvador, 2013.

SANTOS, B. S. Renovar a teoria crítica e reinventar a emancipação social. São Paulo, Boitempo, 2007.

SÃO PAULO. Lei no 12.730, de 11 outubro 2007. Proíbe o uso telefone celular nos estabelecimentos de ensino do Estado, durante o horário de aula. Disponível em: https://www.al.sp.gov.br/norma/74333. Acesso em: 18 maio 2020.

SÃO PAULO. Lei n 16.567, de 06 de novembro de 2017. Altera a Lei no 12.730, de 11 outubro 2007, que proíbe o uso de telefone celular nos estabelecimentos de ensino do Estado, durante o horário de aula. Disponível em:

https://www.al.sp.gov.br/norma/?tipo $=$ Lei\&numero $=16567 \& a n o=2017$. Acesso em: 18 maio 2020.

Salete de Fátima Noro Cordeiro: Possui graduação em Pedagogia pela Universidade Federal de Santa Maria (1998), mestrado em Educação pela Universidade Federal de Santa Maria (2002) e doutorado em Educação pela Universidade Federal da Bahia (2014). Pós-Doutorado (2020) Università Degli Studi Della Tuscia- Unitus- Itália. Atualmente é professora adjunto 4 da Faculdade de Educação da Universidade Federal da Bahia.

Orcid: https://orcid.org/0000-0003-4810-9032

E-mail:snoro2@gmail.com

Maria Helena Silveira Bonilla: Mestre em Educação nas Ciências pela Unijuí; Doutora em Educação pela UFBA; Professora titular da Faculdade de Educação da Universidade Federal da Bahia; Líder do grupo de pesquisa Educação, Comunicação e Tecnologias GEC/UFBA.

Orcid: http://orcid.org/0000-0002-0137-6363

E-mail: bonilla@ufba.br

Este periódico utiliza a licença Creative Commons Attribution 3.0, para periódicos de acesso aberto (Open Archives Initiative - OAI).

' Pesquisa financiada pela Coordenação de Aperfeiçoamento de Pessoal de Nível Superior Capes - Brasil, no âmbito do Programa CapesPrint, edital no 41/2017, processo no $88887.466410 / 2019-00$, e edital CNPq - CHSSA 2016, processo número 440065/2017-8. 